DOI: 10.4322/978-65-89910-16-9-01

\title{
A IMPORTÂNCIA DA LIDERANÇA MOTIVACIONAL PARA O DESENVOLVIMENTO NO TRABALHO: estudo de caso na empresa Brasil Lopes Sociedade Individual de Advocacia
}

\author{
Ananda Brito Mesquita ${ }^{1}$ \\ Elizama Moreira Licar ${ }^{2}$ \\ Jaqueline Pimentel ${ }^{3}$ \\ Maria do Carmo Aranha ${ }^{4}$ \\ Maiane Oliveira Souza Estrela ${ }^{5}$ \\ Sarah Hanna Morais Braga ${ }^{6}$
}

${ }^{1}$ Discente do curso de Ciências Contábeis da Faculdade Edufor. E-mail: mesquitamoraes33@gmail.com

2 Discente do curso de Ciências Contábeis da Faculdade Edufor. E-mail: elizamalicardeandrade@gmail.com

${ }^{3}$ Docente da Faculdade Edufor. E-mail: jaqueline.pimentel@edufor.edu.br

${ }^{4}$ Discente do curso de Ciências Contábeis da Faculdade Edufor. E-mail: docarmoaranha@gmail.com

${ }^{5}$ Discente do curso de Ciências Contábeis da Faculdade Edufor. E-mail: maiane_oliveira@hotmail.com

${ }^{6}$ Discente do curso de Ciências Contábeis da Faculdade Edufor. E-mail: sarahmoraisbraga@gmail.com 


\section{RESUMO}

Existem alguns métodos encontrados em determinadas organizações, baseados em autoritarismo o que levam o indivíduo a adequar-se à organização sem dar espaço para que este se adapte e anule qualquer iniciativa; é aquela do tipo "ordens são para ser cumpridas e não questionadas". Com este modelo, as medidas a serem tomadas nas organizações crescem e se tornam bem mais complexas, percebe-se um grande aumento de pressão nos níveis mais baixos, há restrições de liberdade e ação, para a decisão, e muitos outros em seu ritmo acelerando com algumas mudanças. Isso pode agravar muito o equilíbrio entre relações desenvolvendo várias crises de ansiedades e tensões cada vez maiores. Um líder interessado deve sempre contribuir, pois ele precisa sempre conhecer quais são os valores que estão vigentes na organização e os valores de seus colaboradores, entendendo que deve atuar para compreender o que são prioridades e, buscando traçar caminhos que permitam alcançar os objetivos finais.

Palavras-chave: Líder. Métodos. Decisão. Organizações.

\section{ABSTRACT}

There are some methods found in certain organizations, based on authoritarianism that lead the individual to adapt to the organization without giving space for it to adapt and cancel any initiative; it is the "orders are to be carried out and not questioned" type. With this model, the measures to be taken in organizations grow and become much more complex, there is a great increase in pressure at the lower levels, there are restrictions on freedom and action, for the decision, and many others at their accelerating pace with 
some changes. This can greatly aggravate the balance between relationships, developing several crises of increasing anxiety and tension. An interested leader must always contribute, as he always needs to know what are the values that are in force in the organization and the values of his collaborators, understanding that he must act to understand what are priorities and, seeking to trace paths that allow to reach the final objectives.

Keywords: Leader. Methods. Decision. Organizations.

\section{INTRODUÇÃO}

$\mathrm{Na}$ atual conjuntura em que vivem as organizações, percebem-se os avanços tecnológicos e alterações no que diz respeito aos processos que ocorrem no cenário atual, como muitas mudanças acontecendo em escala exponencial. Observa-se que o papel do líder surge com muita importância na gestão da empresa e como fator influenciador no comportamento de seus liderados. Isso faz com que o indivíduo que ocupa esse papel, se torne cada vez mais eficiente e traga novas teorias e conceitos para este ambiente organizacional. Destaca-se a necessidade da influência da liderança no que diz respeito às teorias motivacionais e seu estilo de liderança, de forma que assegure a empresa o sentimento, 
comprometimento e valorização de todos os envolvidos nos processos que ela desenvolve.

Baseado no exposto e com suporte em pesquisas bibliográficas e questionários aplicados na empresa Brasil Lopes Sociedade Individual de Advocacia com foco na temática sobre a importância da liderança motivacional para o desenvolvimento no trabalho, o presente artigo tem como objetivo discorrer sobre a influência da liderança para o alcance de resultados, bem como sobre as teorias motivacionais e estilos de liderança, além de destacar a importância do líder para garantir o desenvolvimento de sua equipe.

Tem-se, portanto, como problema de pesquisa, o seguinte questionamento: Qual o papel do líder para o desenvolvimento da equipe? Essa é a principal questão problematizadora para analisar-se a preocupação dos líderes das organizações em manter um nível satisfatório na motivação de seus empregados, para que alcancem os melhores resultados. Espera-se, assim, que desta forma se possa entender que não somente a tecnologia, estratégias e um processo bem avaliado trarão a empresa os ganhos esperados, e busca-se manter um bom 
relacionamento com todos os colaboradores, tornando mais agradável possível o ambiente de trabalho.

Pretende-se então, desfazer a antiga ideia de que remuneração e hierarquia eram as fundamentações para motivação de liderados e passa-se a pensar que a qualidade de vida e bem-estar no ambiente organizacional tornam-se imprescindíveis para o alcance de resultados, bem como não se pode deixar de avaliar o nível de confiança repassado pelo líder a sua equipe, pois ele é capaz de reduzir as incertezas do trabalho e torna-se referência motivacional na medida em que a expectativa dos colaboradores aumenta e de que o esforço leva a satisfação de todas as necessidades.

Desta forma, o líder torna-se responsável pela permuta de ideias e experiências, na busca pelo objetivo central, pois através de sua competência e habilidades, gerará nos funcionários confiança e credibilidade, de forma que os façam seguir.

Neste ponto, o líder deverá ser capaz de ouvir, de ajudar a estabelecer quais são suas necessidades, facilitando sua resolução e delegando tarefas de forma adequada. Justifica-se esse estudo orientado para 
análise dos fatores motivacionais das competências e habilidades do líder, analisando o cenário organizacional em que estão inseridos, na forma como reagem e desenvolvem seus processos e identificando-se vários tipos de liderança, sobre as quais também desenvolveremos conceitualmente, desta forma conseguiremos atingir a compreensão de como atingir bons resultados da equipe a partir de políticas.

\section{REFERENCIAL TEÓRICO}

Para dar apoio teórico a pesquisa exposta, apresentam-se comtempladas posteriormente questões que abordam sobre gestão de pessoas, costume corporativo, poder e incentivo, bem como, a comparações e análises entre elas.

\subsection{Liderança}

Para Vecchio (2008), esse tema diz respeito a aspectos corporativos e societários mais longos, como a arranjo das organizações e as ameaças ambientais que influenciam o costume e ações das pessoas e, 
confrontando essas partes vivas das instituições, prontamente refletem na organização, estando juntos pelo grupo que cerca o empreendimento e pela sociedade a que ela pertença.

Um colaborador que tem suas expectativas cumpridas produz mais, contribuindo instantaneamente com a empresa em que está inserido, por meio de uma personificação positiva, acompanhando, assim, a qualidade da gestão de pessoas utilizada para o fortalecimento da imagem da empresa.

Figura 01 - Resumo de Pipeline de liderança

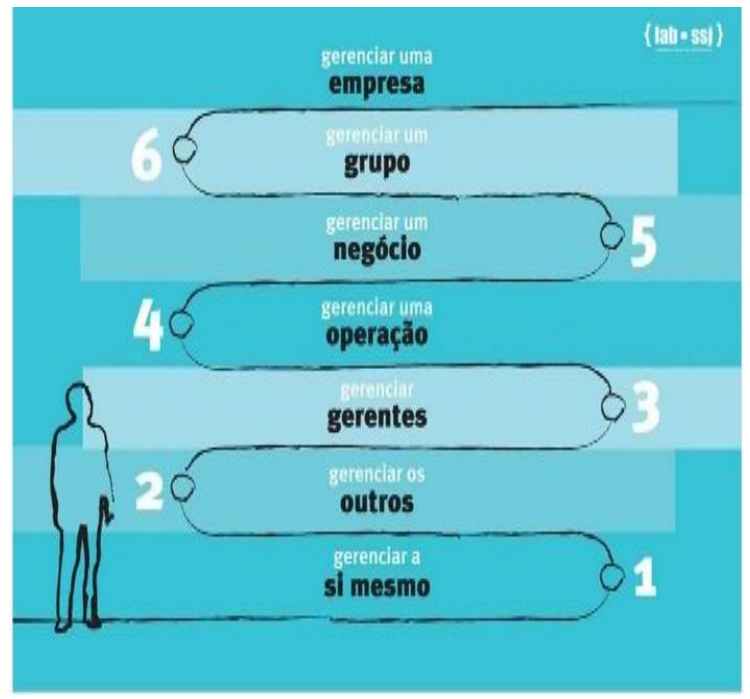

Fonte: CHARAN (2009, pg.03.) 
É primordial discernir os atributos e as armadilhas relacionadas a qualquer pessoa, não somente aquelas contra os seus líderes, mas também aquelas armadilhas aos pares, chefes imediatos e subordinados.

Imagine um empreendimento no qual mais da metade dos gestores em cada curva está lidando com capacidades, utilidades de momento e recursos profissionais inadaptados para o grau que dominam; ou eles deslocaram um ponto e nunca assimilaram o que necessitavam saber ou estão apegados a um remoto modo de controlar que ficou aprovado para eles no passado.

Em algumas empresas, pelo menos metade dos colaboradores em posição de liderança está trabalhando bem abaixo do patamar apropriado. Estes, até tem a capacidade de serem líderes, mas essas capacidades não estão sendo colocadas em prática.

Com o passar das épocas as empresas optam por usos de liderança conforme argumentos da gerência de pessoas, onde o colaborador é percebido não somente como uma parte do modelo corporativo, mas sim como ser humano, onde o líder tem que referir-se com certa cortesia 
e precisa dar assistência para conseguir os avanços que a empresa espera desse empregado.

Pode-se, inclusive, descrever a liderança como sendo o método pelo qual uma pessoa pode persuadir outras a partilharem suas ideias e/ou atos, e conseguir a resolução de algo por meio das demais pessoas, bem como a possibilidade de fazer com que a população se envolva espontaneamente em determinados afazeres para o cumprimento de metas coletivas.

Gerenciar e conseguir resultado através de mais pessoas, é instigar pessoas ou grupos de pessoas para que esses compartilhem instrumentos para conquistar um destino comum, é a utilização de todos os meios acessíveis para fazer um incentivo entre os liderados e a realização das metas gerais e, também, controlar as emoções para poder administrar a própria motivação e a dos liderados (LEVEK; MALSCHITZKY, 2002).

\subsection{Características de líder}

Escritores recentes nos apontam vários pensamentos e situações mediante 0 argumento liderança ocorrendo que, nesta investigação, optou-se 
pelo princípio dos sinais de líder e os costumes de liderança marcados nas teses transformacionais.

Que são quatro características de um líder:

Autoritária - o líder assume inteiramente as providências sozinho, sem mediações dos liderados; (2) Consultiva - o líder consulta os liderados para sustentar a resolução, no caso a definição é um tipo de eleição em que os liderados disputam juntamente qual a melhor alternativa; Benevolente - já diz que o líder tem a segurança, mas percepção os submissos. Ou seja, a sua intrepidez tem clara poder dos liderados; (4) Democrática Participativa o líder e os liderados partilham a tomada de decisão.

Relativamente aos usos de liderança, faz-se fundamental entender as Teorias Transformacionais, que se destacam entre as abordagens das características de liderança. O líder desse tipo exercita um grande grau de importância nos seguidores a ponto de fazer com que eles avancem além de seu próprio individualismo para cooperarem rumo à execução da missão estabelecida.

Segundo Alves (2009), além de conservarem carisma, os líderes transformacionais caracterizam-se pela importância criada (são percebidos pelos seus 
seguidores como padrões a serem seguidos, incluindo um grande direito de comando sobre os liderados), atenção individualizada (valorizam cada membro da equipe, preocupando-se com os direitos pessoais e profissionais destes), estimulação mental (estimulam a inovação e aperfeiçoamento da equipe no nexo de esclarecer dificuldades existentes) e estimulo inspiradora (motivam e conduzem os liderados a encararem fortes afrontas, originando grandes expectativas).

Liderança Laissez-faire (palavra de origem Francesa) pode ser discernida como a "negação da liderança" ou "deixai fazer", já que esse tipo de líder deixa decidir questões ou assumir ocupações.

São três categorias referentes aos resultados da liderança, que são o - Esforço extra, em que o líder leva os subordinados a executarem mais que o previsto, ultrapassando as próprias expectativas; - Eficácia, que ocorre quando o líder valoriza as precisões da organização como um todo, inclusive de cada membro do grupo, incluídos em altos níveis de eficácia; - Satisfação, que se refere à amplitude do líder em permitir um bom clima no local trabalhista e em alcançar um elevado grau 
de compensação dos liderados em relação ao seu estilo de liderança (ALVES, 2009). Buscar por ferramentas que possam aumentar o cumprimento do funcionário no ambiente trabalhista, tendo em observação os elementos particulares do funcionário, as características das funções atribuídas e os negócios da entidade.

O líder pode lidar suas habilidades interpessoais para persuadir positivamente no incentivo de seus apreciadores, sendo primordial pensar no embate da liderança no incentivo para o trabalho. A segurança leva certo tempo para ser completa e, à medida que analisamos uma pessoa, a segurança vai ampliando e tendemos estimulando perspectivas positivas sobre essa relação.

A dignidade que se atribui à disposição de admitir e defende suas ideologias e grupo e por fim, e não muito importante, a amplitude, onde você conjectura que a outra pessoa tem total segurança em você. A equipe, bem como a importância da liderança sobre a mesma, possibilitará dirigir as pessoas envolvidas nas medidas, que são prontamente atingidas por esse desdobramento e, ainda, 
dar instruções, unindo-se a elas ou procurando mudanças.

Entender como se apresentam as relações das pessoas que compõem as equipes, principalmente se a energia do líder é percebida pelos seus liderados como estimulante à sua motivação, se prova intensamente relevante, relacionada a ação de acrescentar entendimento aos líderes e administradores de grupos sobre a alegação de seus empregados.

Líderes buscam a gerenciar o local de treinamento com objetivo de enriquecer a eficácia dos seus liderados, sem desordenar seu modo de autoridade, tendo suas convicções para os subordinados.

\section{METODOLOGIA}

Com o objetivo de obter resultados que nos servissem como embasamento para este estudo de caso, foram aplicados questionários com os quais pudemos identificar o estilo de liderança praticado na empresa Brasil Lopes Sociedade Individual de Advocacia, bem como pudemos mensurar o nível de satisfação dos 
funcionários que responderam ao questionário anonimamente.

Portanto, para alcançarmos o resultado do estudo desenvolvido foram feitas pesquisas com abordagem qualitativa, onde tivemos uma percepção dos fatores que contribuem para o bom desempenho de um trabalho em equipe e os caminhos percorridos para tais fatos.

Através de pesquisas já realizadas, leitura de materiais escritos por profissionais experientes e com competência para discorrer sobre o assunto, pudemos identificar a trajetória necessária a serem explorados por profissionais participantes dos processos, sendo estes gestores ou pessoas subordinadas a um gestor, analisando as teorias motivacionais, conceitos de liderança, cenários organizacionais, tipos de organizações e clima organizacional.

As etapas de análises do conteúdo foram feitas de forma que se estabeleceu tal prática, exploraram-se materiais e transcreveram-se as interpretações retiradas dos elementos bibliográficos, bem como feito estudo de caso na empresa Brasil Lopes Sociedade Individual de Advocacia com aplicação de questionários com as 
seguintes perguntas: Sabe quando deve apoiar e aconselhar? Sabe quando deve da autonomia? Fornece os recursos necessários ao desempenho das tarefas? Sabe ouvir seu liderado? Facilita o diálogo com seu liderado? Reconhece os bons desempenhos? Cria um ambiente de trabalho onde as pessoas se sentem bem? Serve de exemplo a sua atitude de colaboração com os outros? Está disponível a dar apoio quando necessário? Partilha e dá visibilidade a equipe quando esta alcança o sucesso? Consegue realizar negociação ganha-ganha com a equipe?

Através do qual obtivemos informações para embasarmos esta pesquisa com o intuito de demonstrar a importância da liderança motivacional, foi feita a elaboração do questionário, voltado para líderes liderados da empresa Brasil Lopes Sociedade Individual de Advocacia, que desenvolve atividades no segmento de assessoria jurídica e cobrança de taxas condominiais possuindo na posição de líder apenas um diretor, o senhor Bruno Brasil e três indivíduos na posição de liderados.

O objetivo destes questionários foi identificar o nível de aplicação das teorias apresentadas nesta pesquisa, 
bem como os resultados atingidos pela equipe, tanto no que diz respeito aos anseios do líder quanto dos liderados.

Trata-se de uma metodologia onde o fenômeno é experiência, ou seja, é uma pesquisa desenvolvida dentro de um determinado contexto, onde se busca ter uma determinada compreensão.

Nessa pesquisa, o que se destacará será 0 conhecimento que se tem a respeito de um determinado assunto. Portanto ela não apresentará uma realidade real e total, será apenas um recorte que mostrará parte de uma realidade com a intenção de facilitar o entendimento a respeito de um determinado fenômeno. Recortes estes que poderão ser extraídas através de idas ao campo, verificações in loco e aplicações de questionários, de forma que se possa embasar uma pesquisa para posteriormente analisarem-se os dados coletados.

Esse modelo de pesquisa deve levar em consideração três procedimentos que serão primordiais para se definir a relevância do assunto a ser pesquisado. São eles: Justificativa - apresenta-se importância teórica do assunto a ser investigado. Procedimentos - questionase qual a melhor forma para coleta de dados a ser 
utilizado. Questões - o levantamento de quais questões refletiu a linha de investigação.

\subsection{Resultados}

Quanto aos funcionários que responderam aos questionários, trata-se de duas secretárias, com idade de 28 e 29 anos que responderam de forma positiva a perguntas sobre seus níveis de satisfação quanto a sentirem-se apoiadas e aconselhadas e receberem autonomia suficiente para realização das suas tarefas.

Segundo as mesmas, dispõem de recursos que precisam e quando necessários são ouvidas pelo seu líder, de forma que mantém o diálogo aberto, fazendo-as sentirem - se bem em seu ambiente de trabalho. De acordo com as respostas dadas, seu líder é modelo no que diz respeito à colaboração com os outros e as apoia quando necessário. Sentem-se participantes e reconhecidas quando o sucesso é alcançado pela equipe.

No entanto, uma das entrevistadas respondeu não se sentir reconhecida pelo seu bom desempenho e nem seu desenvolvimento profissional facilitado pela empresa em que atua. 
O líder, do sexo masculino, com idade de 39 anos, exerce a função de advogado, sendo ele o proprietário da empresa, respondeu a todas as questões levantadas no questionário com um sim. Fato este que diverge da visão que uma de suas funcionárias tem a respeito de reconhecimento do seu bom desempenho e facilitação de seu desenvolvimento profissional. Neste caso, sugere-se atenção por parte do líder, e reavaliação de sua postura diante dos seus liderados, buscando sempre uma melhoria nesta relação, de forma que a confiança seja estabelecida e a estima desta funcionária seja elevada ao nível de satisfação pessoal por ela almejada.

Ressalta-se que cabe ao gestor a identificação das dificuldades enfrentadas pelos seus funcionários, de forma que possa favorecer a solução das mesmas, e o indivíduo feliz e satisfeito possa render resultados positivos a empresa. Em se tratando do líder reconhecer o desempenho da colaboradora, o que falam os autores. A pesquisa bibliográfica serve para embasar e fundamentar a linha de adotada pelos pesquisadores.

\section{CONSIDERAÇÕES FINAIS}


No mundo atual o tema liderança tem grande importância para gestão organizacional. O ciclo de vida das organizações muitas vezes depende exclusivamente de líderes, que têm todo o compromisso de motivar e tentar incentivar todos os colaboradores para 0 desenvolvimento e crescimento dentro da organização.

O líder de hoje procura desenvolver um trabalho funcional de extrema importância dentro das empresas, onde procura trabalhar em equipe com maior cooperação de todos, além de tomar decisões importantes e racionais, pois nem sempre agimos pela emoção e sim pela razão. O mesmo deve ser aceito e compreendido por toda equipe, pois ele é o exemplo que todos devem seguir.

A finalidade é mostrar se no nosso cotidiano, as empresas que estão ao alcance de nossa realidade, praticam a liderança, constatar se ela faz diferença dentro da organização e se os líderes com seu poder de persuasão conseguem influenciar seus liderados nas tomadas de decisões.

A liderança possui atributos importantes para as organizações e empresas bem-sucedidas devem parte do 
sucesso à liderança e consequentemente aos seus líderes, pois eles são fatores indispensáveis para o desenvolvimento e comprometimento dos colaboradores. 


\section{REFERÊNCIAS}

ALVES, A. S. V. Estilo de liderança da líder do conselho executivo numa escola básica dos $2^{\circ}$ e $3^{\circ}$ ciclos pública da região autônoma da Madeira. Funchal, 2009. Dissertação (mestrado em Administração Educacional). Universidade da Madeira. Disponível em: <http://www.citma.pt/Uploads/Armando\%20Alves.pdf >. Acesso em: 14/05/2021.

CHARAN, DROTTER \& NOEL Pipeline de Liderança. Ano de publicação da primeira edição no Brasil: 2009; Elaborado por: Reno Schmidt; dezembro de 2013. ECCHIO, R. P. Comportamento Organizacional, 6o ed., São Paulo, Cengage Learning, 2008.

LAKATOS, E. M.; MARCONI, M. A., Fundamentos de Metodologia Cientifica, 5ª ed., São Paulo, Atlas, 2003.

LEVEK, A. R. H. C.; MALSCHITZKY N. Liderança. In: Gestão do Capital Humano. Coleção Gestão Empresarial. Curitiba - PR: AFESBJ, FAE, Business School, Gazeta do Povo, 2002, pág. 33-46. 